$$
\mathrm{R}^{\prime}-\mathrm{NH}_{2}
$$

fluorescence-tagging reagent

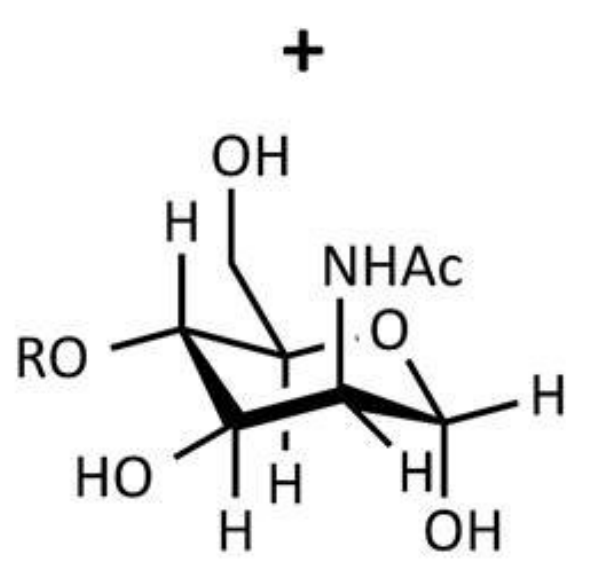

glycan
Schiff's base
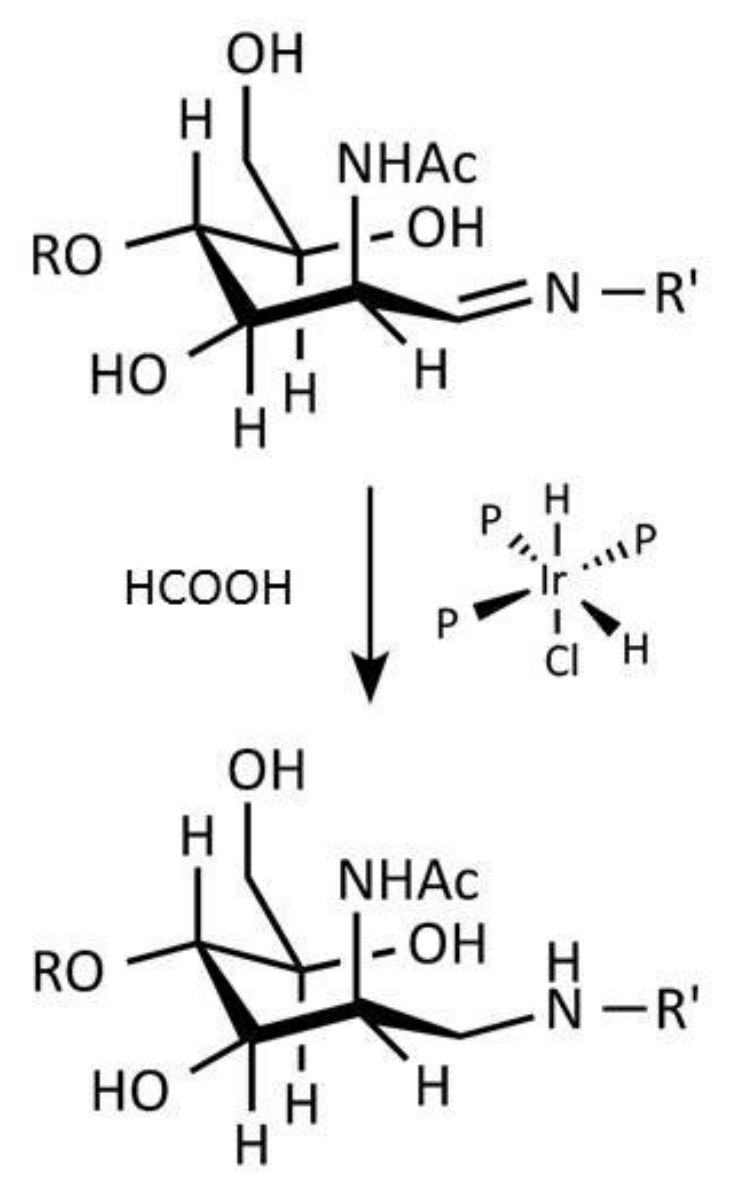

labeled glycan 


\title{
A NOVEL CARBOHYDRATE LABELING METHOD UTILIZING TRANSFER HYDROGENATION-MEDIATED REDUCTIVE AMINATION
}

\author{
Zsuzsanna Kovács ${ }^{1}$, Gábor Papp ${ }^{2}$, Henrietta Horváth ${ }^{3}$, Ferenc Joó ${ }^{2,3}$ and András Guttman ${ }^{1}$ \\ ${ }^{1}$ Horváth Csaba Laboratory of Bioseparation Sciences, University of Debrecen, Hungary \\ ${ }^{2}$ Department of Physical Chemistry, University of Debrecen, Hungary \\ ${ }^{3}$ MTA-DE Homogeneous Catalysis and Reaction Mechanisms Research Group, University of \\ Debrecen, Hungary
}

\begin{abstract}
One of the most frequently used high-resolution glycan analysis methods in the biopharmaceutical and biomedical fields is capillary electrophoresis with laser-induced fluorescence (CE-LIF) detection. Glycans are usually labeled by reductive amination with a charged fluorophore containing a primary amine, which reacts with the aldehyde group at the reducing end of the glycan structures. In this reaction, first a Schiff base is formed that is reduced to form a stable conjugate by a hydrogenation reagent, such as sodium cyanoborohydride. In large scale biopharmaceutical applications, such as clone selection for glycoprotein therapeutics, hundreds of reactions are accomplished simultaneously, so the $\mathrm{HCN}$ generated in the process poses a safety concern. To alleviate this issue, here we propose catalytic hydrogen transfer from formic acid catalyzed by water-soluble iridium(III)- and ruthenium(II)-phosphine complexes as a novel alternative to hydrogenation. The easily synthesized water-soluble iridium(III) and the ruthenium(II) hydrido complexes showed high catalytic activity in carbohydrate labeling. This procedure is environmentally friendly and reduces the health risks for the industry. Using carbohydrate standards, oligosaccharides released from glycoproteins with highly sialylated (fetuin), high mannose (ribonuclease B) and mixed sialo and neutral (human plasma) N-glycans, we demonstrated similar labeling efficiencies for iridium(III) dihydride to that of the conventionally used sodium cyanoborohydride based reaction. The derivatization reaction time was less than 20 min with no bias towards the above mentioned specific glycan structures.
\end{abstract}

\section{Highlights}

- Novel transfer hydrogenation mediated reductive amination process

- No HCN release during labeling reaction

- Fast, non-selective labeling of all major N-glycan subclasses 
Abbreviations: LIF - laser induced fluorescence; APTS - 8-Aminopyrene-1,3,6-trisulfonate; $m$ tppms - monosulfonated triphenylphosphine Na salt

Keywords: N-glycans, fluorophore labeling, biopharmaceuticals, transfer hydrogenation

\section{Introduction}

Protein-linked glycans are participating in important biological processes such as cell-cell interactions, receptor activation and cell attachment to the extracellular matrix, therefore represent an important field for the biopharmaceutical industry [1]. Recent advances in understanding the role of glycosylation of therapeutic proteins and the search for glycobiomarkers in specific diseases have created the need for fast and sensitive highthroughput glycoanalytical methods [2, 3]. To separate and analyze released and subsequently derivatized oligosaccharides, liquid phase bioanalytical methods (liquid chromatography - LC and capillary electrophoresis - CE) are mostly used, in addition to mass spectrometry and NMR based structural elucidation techniques. Since the application of liquid phase separation methods with optical or mass spectrometric detection for the characterization of complex carbohydrates is hindered by the lack of chromophore/fluorophore moieties and their poor ionization properties, a wide variety of derivatization strategies with a large number of different labels have been introduced [4].

8-Aminopyrene-1,3,6-trisulfonate (APTS) is one of the most frequently used reductive amination based derivatization agent in capillary electrophoresis, possessing three strong negative charges and great fluorescent properties, therefore very suitable for CE-LIF applications [5, 6]. This label facilitated sensitive detection by excitation with the stable argon-ion or solid state $488 \mathrm{~nm}$ lasers commonly used in commercial CE equipments, also providing good separation characteristics [7]. The detection limit of laser-induced fluorescence (LIF) of APTS labeled sugars in CE is in the low femtomolar range[8]. The most widely applied reducing agents for these reductive amination reactions are sodium cyanoborohydride and 2-picoline borane. Very high yields of oligosaccharide labeling have been reported using these reductive agents [9]. During the first step of the derivatization reaction, the open-ring form of the carbohydrate reversibly reacts with the primary amine group of the dye with the loss of a water molecule, forming a Schiff-base. In a second, irreversible step, the Schiff -base is reduced to stable conjugate as delineated in Figure 1. 
Due to the HCN release associated with the use of sodium cyanoborohydride, alternative reducing agents, such as sodium triacetoxyborohydride $\left(\mathrm{NaBH}(\mathrm{OAc})_{3}\right)[10],[11]$, boranediethylamine and 2-picoline borane have been suggested [9].

Our group has recently developed several high-throughput sample preparation methods for Nglycan labeling and analysis, which required reductive amination-based fluorophore tagging of sugars with APTS. To avoid the generation of the acutely toxic hydrogen cyanide, several substitutes were evaluated to replace the sodium cyanoborohydride as reductive agent. Here, we report on the use of water-soluble $\left[\mathrm{IrH}{ }_{2} \mathrm{Cl}(m \mathrm{tppms})_{3}\right]$ and $\left[\mathrm{RuCl}_{2}(m \mathrm{tppms})_{2}\right]$ complexes, applied as catalysts for equally efficient hydrogenation by $\mathrm{H}$-transfer from formic acid as an alternative to $\mathrm{NaBH}_{3} \mathrm{CN}$ for oligosaccharide labeling by reductive amination.

\section{Materials and Methods}

2.1 Chemicals and reagents: Sodium hydroxide, formic acid, sodium formate, sodium cyanoborohydride (1 M in THF), fetuin (fetal calf serum), ribonuclease B (bovine pancreas) and human plasma were from Sigma-Aldrich (St. Louis, MO). PNGase F was from ProZyme (Hayward, CA). The 8-aminopyrene-1,3,6-trisulfonate (APTS), the standard maltooligosaccharide ladder and the NCHO Carbohydrate Labeling and Analysis kit were from SCIEX (Brea, CA). $\quad\left[\mathrm{IrH}_{2} \mathrm{Cl}(m \mathrm{tppms})_{3}\right]$ (trisodium cis-mer-chloro-dihydridotris(diphenylphosphinobenzene- $m$-sulfonato)iridium(III)) and $\left[\mathrm{RuCl}_{2}(m \text { tppms) })_{2}\right]$ (disodium dichloro-bis(diphenylphosphinobenzene-m-sulfonato)ruthenium(II)) (see structures in Figure 2) were made in house as described earlier in [12] and [13], respectively (Please note that the $\mathrm{Ru}(\mathrm{II})$-complex has a dimeric structure in solid state as shown in Figure 2, however, for the sake of simplicity we refer to here as a monomer). Both complexes are highly water-soluble and can be synthesized easily from their halide precursors of $\mathrm{IrCl}_{3} \cdot 3 \mathrm{H}_{2} \mathrm{O}$ [12] and $\mathrm{RuCl}_{3} \cdot 3 \mathrm{H}_{2} \mathrm{O}$ [13], respectively, in reaction with monosulfonated triphenylphosphine ( $m$ tppms [13]).

2.2 Sample Preparation: The following reaction mixture was used as derivatization control: $6 \mu \mathrm{L}$ of $40 \mathrm{mM} 8$-aminopyrene-1,3,6-trisulfonic acid in $20 \%$ acetic acid and $1.5 \mu 1$ of $1 \mathrm{M}$ sodium cyanoborohydride (in THF) were added to the dried sugars [14] and incubated at $55^{\circ} \mathrm{C}$ for $60 \mathrm{~min}$. For Ir- or Ru-complex based transfer hydrogenation-mediated reductive amination, $6 \mu \mathrm{L}$ of $40 \mathrm{mM}$ 8-aminopyrene-1,3,6-trisulfonic acid in 20\% acetic acid and 1.5 $\mu \mathrm{L}$ of concentrated (98\%) formic acid, $1.5 \mu \mathrm{L}$ of water-soluble iridium(III) dihydride complex $(5 \mathrm{mg} / \mathrm{mL})$ or $1.5 \mu \mathrm{L}$ of water-soluble ruthenium complex $(5 \mathrm{mg} / \mathrm{mL})$ were added to 
the dried sugar samples followed by incubation between at $55^{\circ} \mathrm{C}$, as specified under the actual application descriptions. The labeled samples were partitioned from the excess labeling dye with the magnetic beads provided in the Fast Glycan Sample Preparation kit (SCIEX) and immediately used for CE-LIF analysis or stored at $-20^{\circ} \mathrm{C}$.

2.3 Instrumentation: A P/ACE MDQ System (SCIEX) was used to perform all capillary electrophoresis analyses. The separations were monitored by laser induced fluorescence (LIF) detection using a $488 \mathrm{~nm}$ Ar-ion laser with a $520 \mathrm{~nm}$ emission filter. $50 \mathrm{~cm}$ effective length (60 $\mathrm{cm}$ total) $50 \mu \mathrm{m}$ i.d. Bare Fused-Silica (BFS) capillaries were employed with the NCHO separation gel buffer system (both from SCIEX). All separations were accomplished in reversed polarity mode (anode at the detection side) and the samples were pressure injected (1 psi for 5 seconds). The 32 Karat ver 9.1 software (SCIEX) was used for data acquisition and processing.

\section{Theoretical Considerations}

In comparison to hydrogenation with $\mathrm{H}_{2}$ gas or with soluble hydrides, such as $\mathrm{NaBH}_{4}$ or $\mathrm{NaBH}_{3} \mathrm{CN}$ etc., transfer hydrogenation of unsaturated substrates (alkenes, carbonyls, imines, etc.) offers considerable advantages. In this reaction, the hydrogen is directly transferred from a donor molecule (D) to the unsaturated function of the substrate:

$$
\mathrm{DH}_{2}+\mathrm{R}\left(\mathrm{R}^{\prime}\right) \mathrm{C}=\mathrm{N}-\mathrm{R}^{\prime} \rightarrow \quad \mathrm{R}\left(\mathrm{R}^{\prime}\right) \mathrm{CH}-\mathrm{NH}-\mathrm{R}^{\prime \prime}+\mathrm{D}
$$

The most prominent hydrogen donors in use for synthetic purposes are 2-propanol and formates or formic acid (often the combination of the two latter ones). The reaction can be catalyzed by a large variety of homogeneous and heterogeneous catalysts, but phosphine complexes of precious metals are among the most active ones [15].

When using formic acid as hydrogen donor one has to consider the catalytic decomposition of $\mathrm{HCOOH}$ too, yielding $\mathrm{H}_{2}$ and $\mathrm{CO}_{2}$. Please note that the complex is also capable of catalyzing hydrogenation with gaseous $\mathrm{H}_{2}[16]$, albeit, this side reaction does not hinder reduction of the unsaturated substrate, and may require the use of larger amounts of $\mathrm{HCOOH}$ due to the escape of a part of $\mathrm{H}_{2}$ into the gas phase.

Since our earlier studies, using both $\left[\mathrm{RuCl}_{2}(m \mathrm{tppms})_{2}\right]$ and $\left[\mathrm{IrH}_{2} \mathrm{Cl}(m \text { tppms })_{3}\right]$, showed excellent catalytic activities in hydrogenation and transfer hydrogenation of various unsaturated groups $[17,18]$ and in decomposition of formic acid [12], we envisaged their 
applicability in transfer hydrogenation of the imine intermediates of glycan labeling by reductive amination (Figure 1). The use of $\mathrm{Ru}(\mathrm{II})$ - and $\mathrm{Ir}(\mathrm{III})$-complexes is readily facilitated by their good water-solubility. Formic acid and $m$ tppms are non-toxic and handling aqueous solutions of the catalysts does not pose any health hazard either.

\section{Results and Discussion}

Transfer hydrogenhation from formic acid catalyzed by $\left[\mathrm{IrH}_{2} \mathrm{Cl}(m \text { tppms })_{3}\right]$ and $\left[\mathrm{RuCl}_{2}(m \text { tppms })_{2}\right]$ were evaluated as alternatives to reduction by $\mathrm{NaBH}_{3} \mathrm{CN}$ during the labeling of simple and complex carbohydrates by reductive amination. A standard maltooligosaccharide ladder and endoglycosidase released $\mathrm{N}$-glycans from fetuin, ribonuclease $\mathrm{B}$ and human plasma were labeled using the aforementioned two catalysts mediated transfer hydrogenation. The resulting APTS labeled samples were analyzed by CELIF. The electropherograms of the standard maltooligosaccharide ladder using different reducing agent mediated labeling are compared in Figure 3A. For quantitative evaluation, the average peak heights of the maltopentaose (G5 oligomer) were determined. As one can observe, the intensities for APTS labeled maltopentaose peaks were very similar for $\left[\mathrm{IrH}_{2} \mathrm{Cl}(m \text { tppms })_{3}\right]$ and $\mathrm{NaBH}_{3} \mathrm{CN}$, while the use of $\left[\mathrm{RuCl}_{2}(m \text { tppms })_{2}\right]$ in the same molar concentration resulted in lower intensities (Figure 3B).

To test transfer hydrogenation as an alternative and efficient reduction procedure on biologically relevant samples, N-glycans enzymatically released from fetuin, ribonuclease B and human plasma were labeled using $\mathrm{NaBH}_{3} \mathrm{CN}$, and transfer hydrogenation from formic acid catalyzed by $\left[\mathrm{IrH}_{2} \mathrm{Cl}(m \text { tppms })_{3}\right]$ and $\left[\mathrm{RuCl}_{2}(\mathrm{mtppms})_{2}\right]$. As depicted in Figure 4, CE-LIF electropherograms showed similar labeling efficiency of $\mathrm{NaBH}_{3} \mathrm{CN}$ and $\left[\mathrm{IrH}_{2} \mathrm{Cl}(m \mathrm{tppms})_{3}\right]$. $\left[\mathrm{RuCl}_{2}(\mathrm{mtppms})_{2}\right]$ could be also used effectively, however, for similar labeling performance (such as shown in Figure 4) it had to be applied in higher (2.5 fold) concentration. It is important to note that in case of the analysis of the fetuin derived highly sialylated N-glycans, the peak at 11 min was larger (middle and upper traces), suggesting better stability against sialic acid loss.

\section{Conclusions}

In this paper we describe a conceptually novel procedure for labeling of N-glycans by fluorogenic primary amines via reductive amination, based on transfer hydrogenation from formic acid catalyzed by water-soluble phosphine complexes of $\operatorname{Ir}(\mathrm{III})$ and $\operatorname{Ru}(\mathrm{II})$, namely 
$\left[\mathrm{IrH}_{2} \mathrm{Cl}(m \mathrm{tppms})_{3}\right]$ and $\left[\mathrm{RuCl}_{2}(m \mathrm{tppms})_{2}\right]$. These complexes were easy to synthesize and represent highly active catalysts for selective decomposition of formic acid to $\mathrm{H}_{2}$ and $\mathrm{CO}_{2}$. The use of $\left.\mathrm{IrH}_{2} \mathrm{Cl}(m \text { tppms })_{3}\right]$ revealed very similar labeling efficiencies to those observed for the traditionally used reducing agent $\mathrm{NaBH}_{3} \mathrm{CN}$. Conversely, the actually cheaper $\left[\mathrm{RuCl}_{2}(m \text { tppms })_{2}\right]$ showed somewhat lower activity; however, it could also be used advantageously in higher concentrations $(2.5 \mathrm{x})$. Notably, this procedure avoids the release of acutely toxic hydrogen cyanide, therefore, it is more environmentally friendly and eliminates the health risks, which accompanies the use of $\mathrm{NaBH}_{3} \mathrm{CN}$ as reducing agent in large scale use of reductive amination reactions.

On the basis of the promising results of this study, investigations are in progress in our laboratories to find other easily accessible transfer hydrogenation catalysts, which allow rapid sugar labeling by reductive amination under very mild conditions.

\section{Acknowledgement}

The authors acknowledge the support of the Momentum (Lendulet) grant \# 97101 of the Hungarian Academy of Sciences (MTA-PE Translational Glycomics) and the National Research, Development and Innovation Office (NKFIH) (K 116263) grants of the Hungarian Government. This work was also supported by the NTP-NFTÖ-16 project by the Human Capacities Grant Management Office and the Hungarian Ministry of Human Capacities and the BIONANO_GINOP-2.3.2-15-2016-00017 project as well as by the EU and co-financed by the European Regional Development Fund under the project GINOP-2.3.2-15-2016-00008.

\section{Figures}

Figure 1: Sugar labeling reaction with an amino-fluorescent tagging

Figure 2: The water-soluble $\left[\mathrm{RuCl}_{2}(m \text { tppms })_{2}\right]$ and $\left[\mathrm{IrH}_{2} \mathrm{Cl}(m \text { tppms })_{3}\right]$ complexes used in the reductive amination reactions

Figure 3A: CE-LIF separations of APTS labeled maltooligosaccharides using $\mathrm{NaBH}_{3} \mathrm{CN}$ (a), and $\mathrm{HCOOH}$ as hydrogen donor with $\left[\mathrm{IrH}_{2} \mathrm{Cl}(m \mathrm{tppms})_{3}\right]$ (b) and $\left[\mathrm{RuCl}_{2}(m \text { tppms })_{2}\right]$ (c) catalysts. G5 denotes the maltopentaose peak. Conditions: BFS capillary (50 cm effective / 60 cm total length), $50 \mu \mathrm{m}$ i.d., $30 \mathrm{kV}$ separation voltage, reversed polarity, NCHO separation gel buffer, $20^{\circ} \mathrm{C}$ temperature, $1 \mathrm{psi} / 5 \mathrm{~s}$ injection. 
Figure 3B: Labeling intensities for maltopentaose in reductive amination reactions with $\mathrm{NaBH}_{3} \mathrm{CN}$ (dark gray), $\mathrm{HCOOH} /\left[\mathrm{IrH}_{2} \mathrm{Cl}(m \text { tppms })_{3}\right]$ (black) and $\mathrm{HCOOH} /\left[\mathrm{RuCl}_{2}(m \text { tppms })_{2}\right]$ (gray) as a function of time. Reaction temperatures were $55^{\circ} \mathrm{C}$ in all instances.

Figure 4: CE-LIF traces of APTS labeled fetuin (A), ribonuclease B (B) and human plasma (C) N-glycans using $\mathrm{NaBH}_{3} \mathrm{CN}$ (a), $\left[\mathrm{IrH}_{2} \mathrm{Cl}(m \text { tppms })_{3}\right]$ (b) and $\left[\mathrm{RuCl}_{2}(m \text { tppms })_{2}\right]$ (c) as depicted in the relevant electropherograms. Conditions were the same as in Figure 3A.

\section{References}

[1] K. Ohtsubo, J.D. Marth, Cell, 126 (2006) 855-867.

[2] N.H. Packer, C.W. von der Lieth, K.F. Aoki-Kinoshita, C.B. Lebrilla, J.C. Paulson, R. Raman, P. Rudd, R. Sasisekharan, N. Taniguchi, W.S. York, Proteomics, 8 (2008) 8-20.

[3] M. Wuhrer, Expert Review of Proteomics, 4 (2007) 135-136.

[4] L.R. Ruhaak, G. Zauner, C. Huhn, C. Bruggink, A.M. Deelder, M. Wuhrer, Analytical and Bioanalytical Chemistry, 397 (2010) 3457-3481.

[5] N. Callewaert, S. Geysens, F. Molemans, R. Contreras, Glycobiology, 11 (2001) 275-281.

[6] W. Laroy, R. Contreras, N. Callewaert, Nature Protocols, 1 (2006) 397-405.

[7] P. Jackson, The Biochemical Journal, 270 (1990) 705-713.

[8] R.A. Evangelista, A. Guttman, F.T. Chen, Electrophoresis, 17 (1996) 347-351.

[9] L.R. Ruhaak, E. Steenvoorden, C.A. Koeleman, A.M. Deelder, M. Wuhrer, Proteomics, 10 (2010) 2330-2336.

[10] D. Locke, C.G. Bevans, L.X. Wang, Y. Zhang, A.L. Harris, Y.C. Lee, Carbohydrate Research, 339 (2004) 221-231.

[11] D.S. Dalpathado, H. Jiang, M.A. Kater, H. Desaire, Analytical and Bioanalytical Chemistry, 381 (2005) 1130-1137.

[12] G. Papp, G. Olveti, H. Horvath, A. Katho, F. Joo, Dalton Transactions, 45 (2016) 14516-14519.

[13] J.K. Ferenc Joó, Ágnes Kathó, Attila C. Bényei, Tara Decuir, Donald J. Darensbourg, Alex Miedaner and Daniel L. Dubois, Inorganic Synthesis. , 32 (1998), p. 1-8. (1998).

[14] C. Varadi, C. Lew, A. Guttman, Analytical Chemistry, 86 (2014) 5682-5687.

[15] D. Wang, D. Astruc, Chemical Reviews, 115 (2015) 6621-6686.

[16] G. Papp, H. Horvath, G. Laurenczy, I. Szatmari, A. Katho, F. Joo, Dalton Transactions, 42 (2013) 521-529.

[17] F. Joo, Accounts of Chemical Research, 35 (2002) 738-745.

[18] F. Joo, Aqueous Organometallic Catalysis, Kluwer, Dordrecht, The Netherlands (2001.). 
Figure 1.

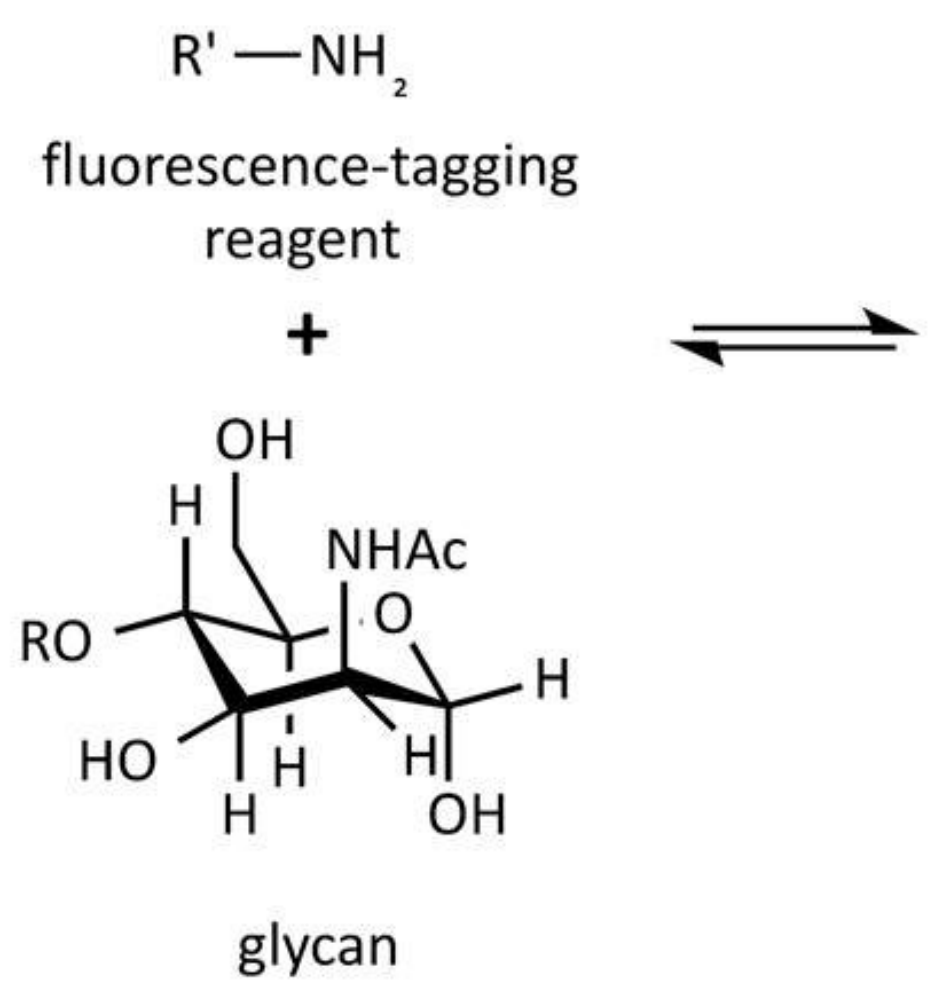

Schiff's base
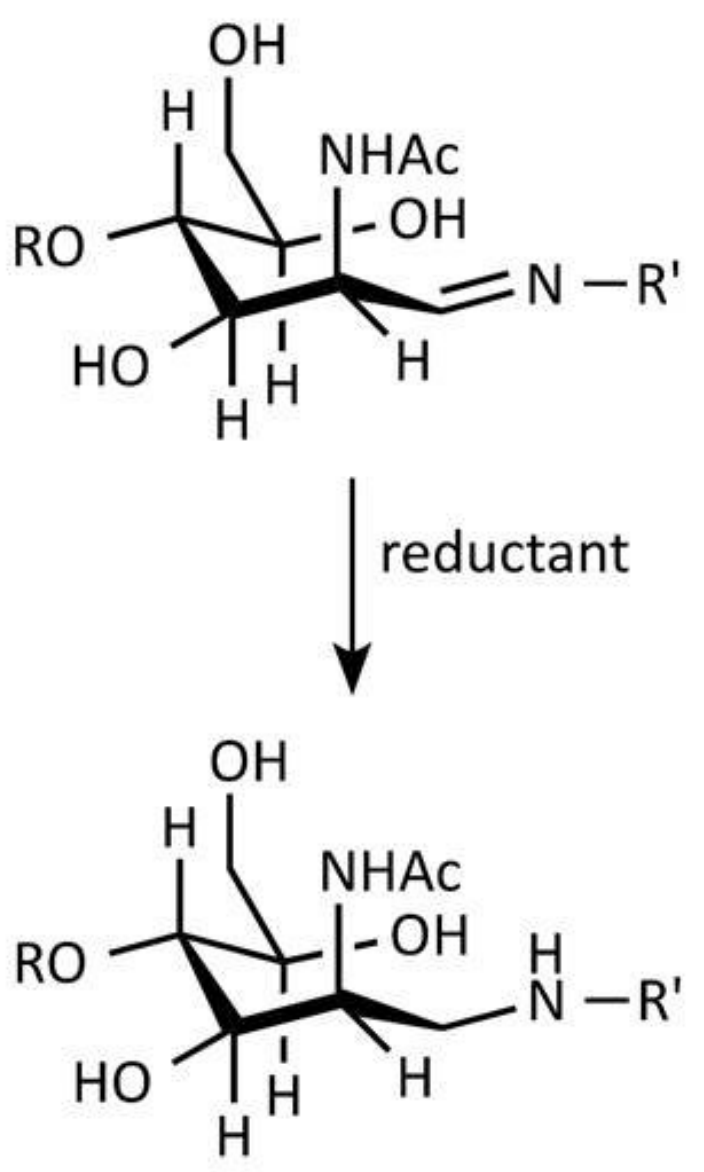

labeled glycan 


\section{Figure 2.}
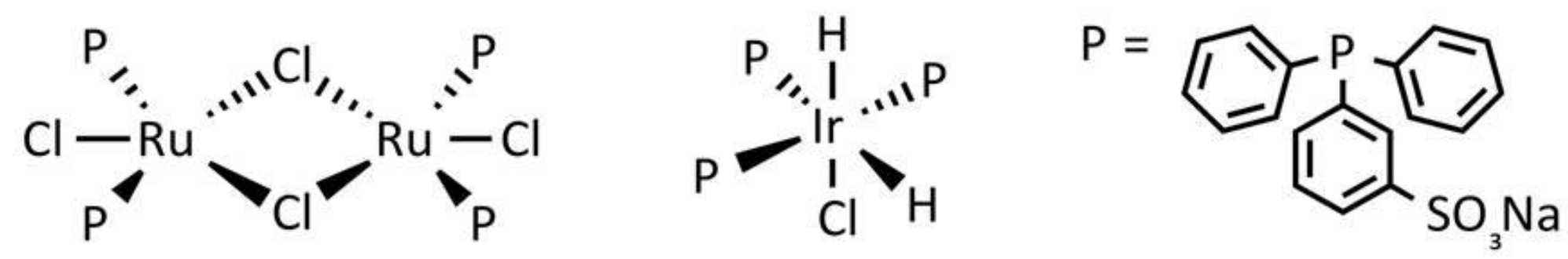
Figure 3A

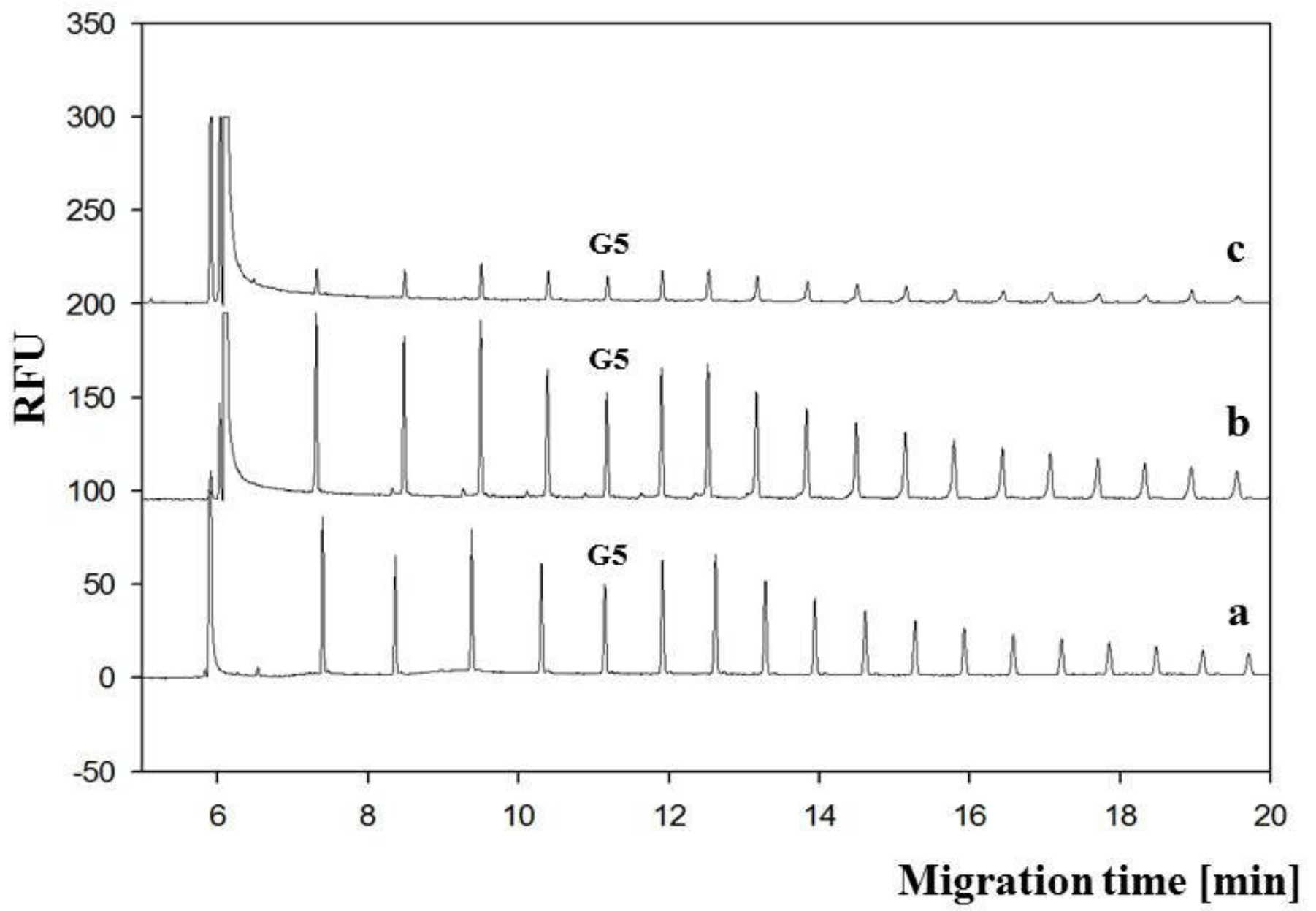


Figure 3B

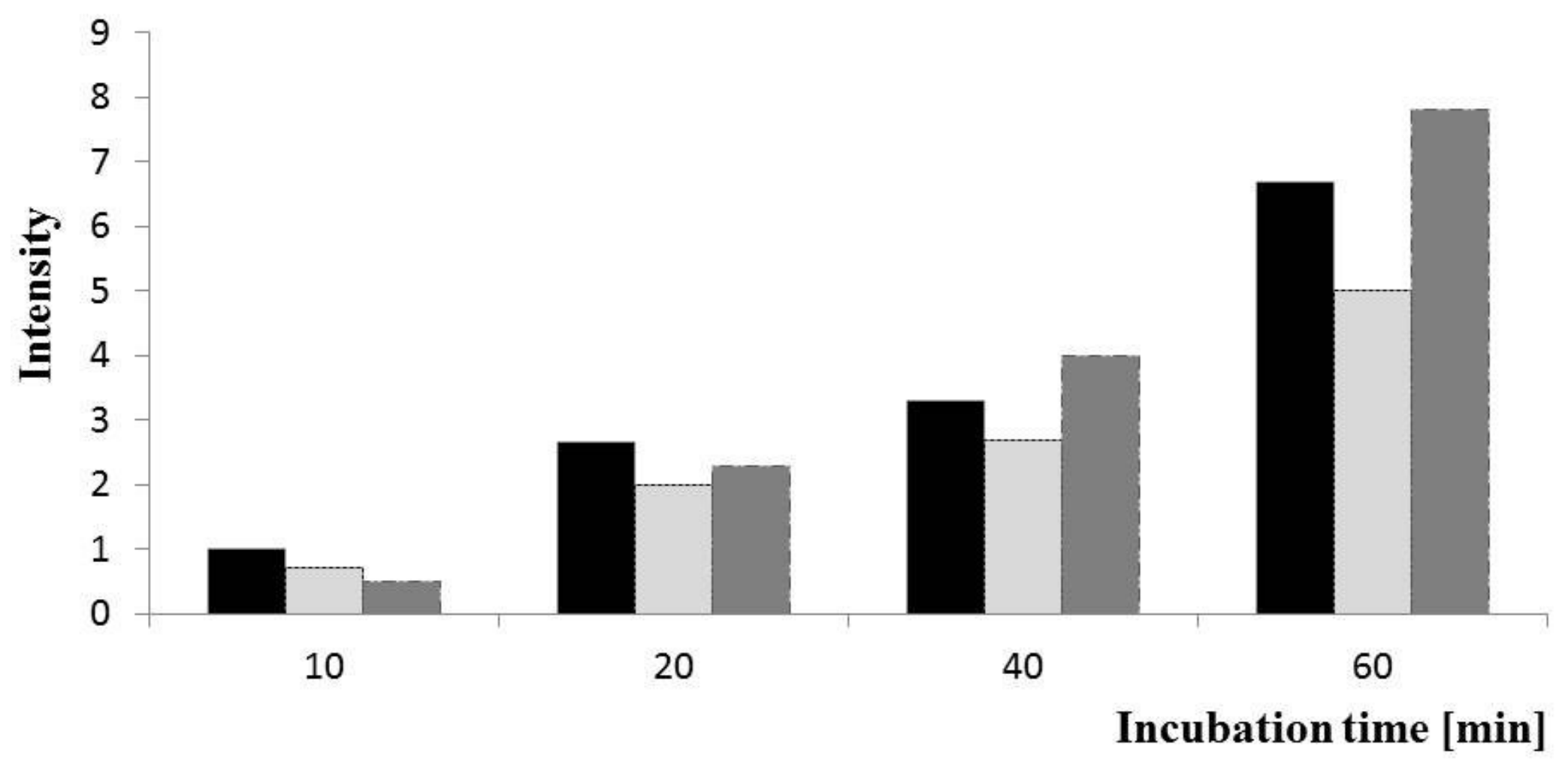


Figure 4.

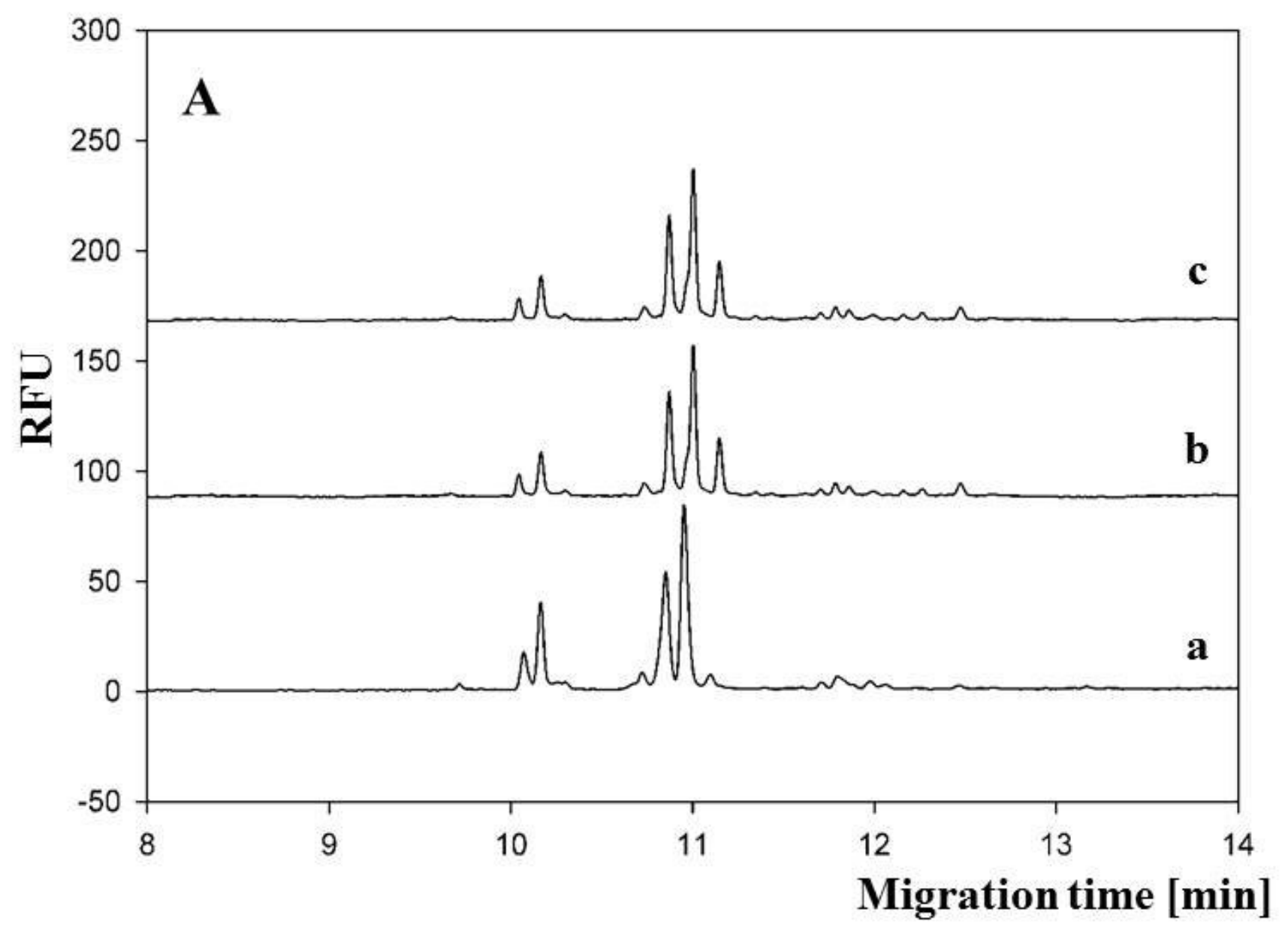


Figure 4.

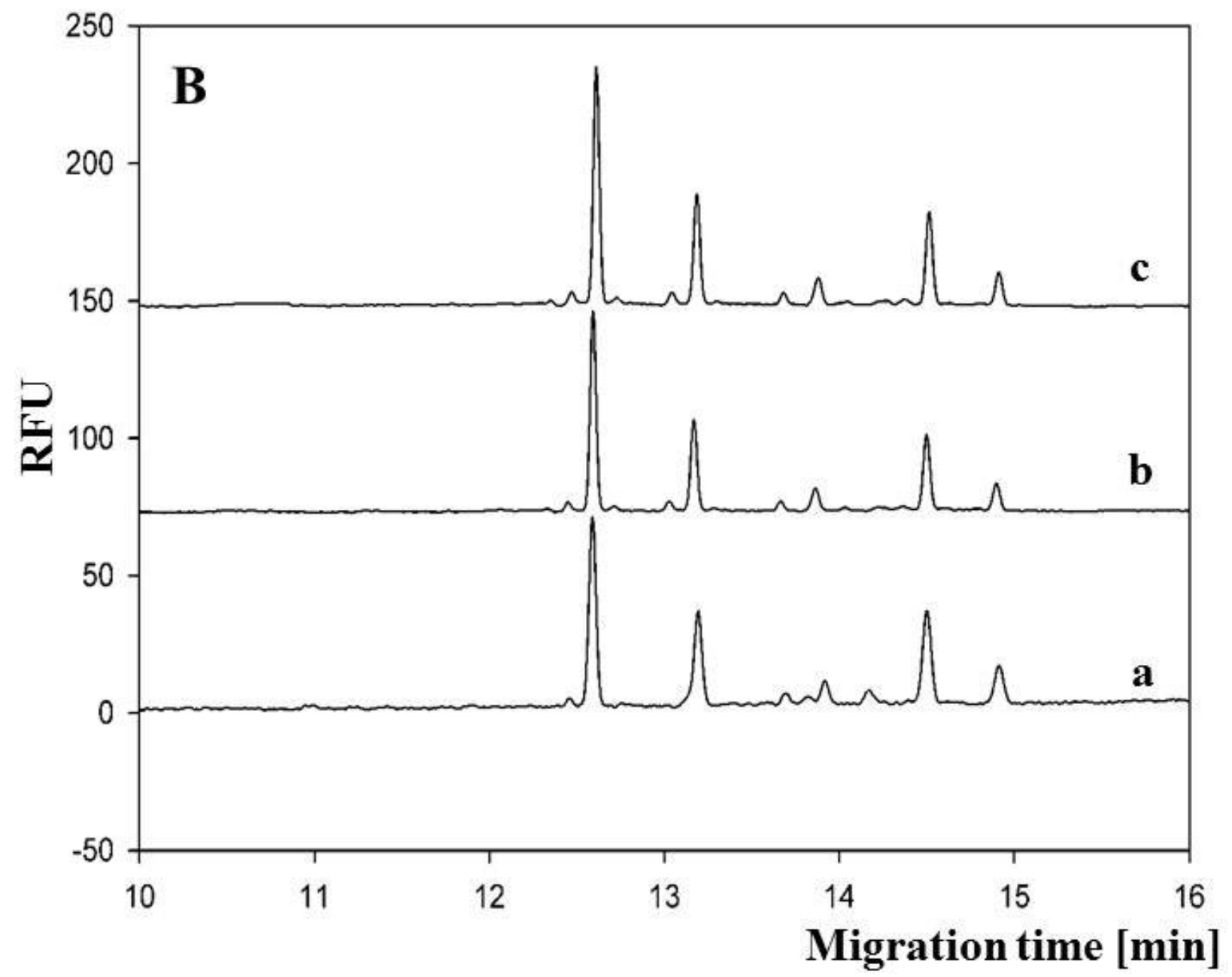


Figure 4.

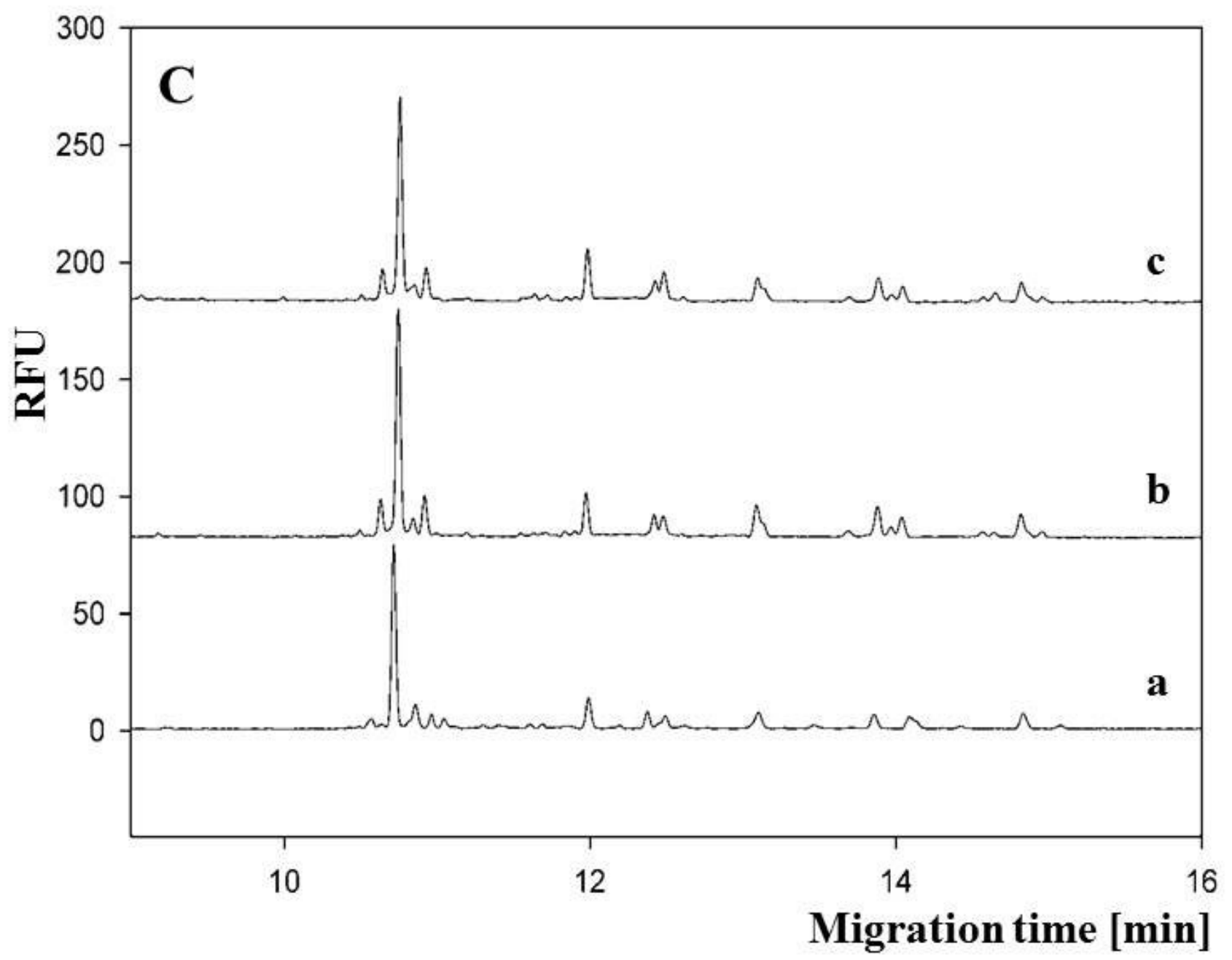




\section{Highlights}

- Novel transfer hydrogenation mediated reductive amination process

- No HCN release during labeling reaction

- Fast, non-selective labeling of all major N-glycan subclasses 